(C) Oxford University Press and Community Development Journal. 2013

All rights reserved. For permissions, please email: journals.permissions@oup.com doi: 10.1093/cdj/bst008

\title{
'Beyond text': exploring ethos and method in co-producing research with communities
}

\author{
Yasminah Beebeejaun, Catherine Durose, \\ James Rees, Joanna Richardson \\ and Liz Richardson*
}

\begin{abstract}
There is a critique of research conducted in communities which fails to include communities in its design and undertaking. In parallel, academic research is increasingly being measured according to its benefit to the wider society. Co-productive research is a response to these challenges which offers a way of recognizing the resource contribution of communities to research and emphasizing the conduct of research 'with' communities rather than 'on' communities. This article identifies the reliance on 'text' in the research process as a barrier to delivering meaningful co-productive research with communities. 'Beyond-text' tools are emerging across academic disciplines and include story-telling, performance, art and photography. Recent research emphasizes the empowering potential of these methods by facilitating greater reflection on the lived experience of those involved. This article looks at examples of research which have employed 'beyond text' methods to consider their potential to deliver co-produced research with communities. It also asks whether it is the application of specific technical approaches and methods, or the underlying ethos within which research is conducted that is most critical to challenging unequal power relationships. It argues that beyond-text methods need to be applied within a wider set of values which re-conceptualize the role of the researcher working with communities.
\end{abstract}

\footnotetext{
*Address for correspondence: Liz Richardson, School of Social Sciences, University of Manchester, Oxford Road, Manchester, MI3 9PL, UK; email: liz.richardson@manchester.ac.uk
} 


\section{Introduction}

There is a continuing critique that community-focused research fails to meaningfully include communities in designing and implementing research (Denis and Lomas, 2003), and often fails to adequately represent the identities and aspirations of communities (Durose, Greasley and Richardson, 2009). There are historical examples of community anger over the ways that communities have been portrayed in research (Gallaher, 1971) and a growing demand to have more input into, and control over, research that is done about them. The implications which flow from a lack of connectivity between research and the communities being researched notably a relevance gap (British Academy, 2010) - are now also being acknowledged within the academic community in the United Kingdom and elsewhere as academics face increasing pressure to demonstrate the social impact of their work.

While participatory approaches now have considerable resonance in research, the reasoning behind the approaches, and their suggested impact are contested. This contestation comes in part from a long-standing epistemological debate about the nature of knowledge and expertise between dominant positivist and alternative non-positivist approaches to research. Some argue that marginalized groups cannot contribute meaningfully to analytical thinking (Richardson and Le Grand, 2002); 'naïve knowledges [are seen as] beneath the required level of [...] scientificity' (Foucault, 1980, p. 82). Some argue that there are many other techniques for making the substantive content of research accountable to the true complexity of participants' views, which do not pose the risks inherent in participation (Wingenbach and Phillips 2004). That the perspectives of research participants can be so glibly dismissed is perhaps indicative of the hidden power dynamics at work (Redwood, 2008, p. 7; Orr and Bennett, 2009) and reflects deeper tensions in how different forms of knowledge are seen, produced and validated.

Others have challenged the lack of evidence on the impact of participatory research (Catalani and Minkler, 2009); as Riger comments, simply 'intending to create social change is no assurance of actually doing so' (1992, p. 736). Ghose (2007) highlights that where attempts at participatory research have been made, continuing structural inequalities, hierarchical dominance and fluctuating resources within spaces for engagement create new divisions within communities. Some are able to skilfully negotiate networks of power to gain an effective voice in decision-making, while other community actors lag behind, and are not able to form relationships in order to secure influence and voice.

Even for advocates of co-production in research, 'formidable barriers' remain (Martin, 2010, p. 213). There are critical questions about the 
'game' of engagement: who is playing, how the dice are loaded and whether it is the right game to play to empower communities (Taylor, 2011). Aldred (2011) has used Appreciative Inquiry and 'World Café' research to critique participatory approaches that may lead to participants being pathologized as having 'entrenched negativity' (p. 63) when raising structurally rooted problems. Community members and researchers may also have differing views on the relationships between research and action (Williamson and de Souza, 2010). Researchers face uncertainty about how to tackle 'epistemological challenges ... arising from the existence of multiple world views' (Umemoto, 2001, p. 17). This includes recognizing researchers and the researched as distinct groups with competing claims to knowledge, how to negotiate power asymmetries and challenge the embedded knowledge hierarchy of the expert versus the layperson (Porter, 2010), as well as embrace the opportunities that 'lie in the unexpected and contingent' (Pearce, 2008, p. 5).

Despite these challenges to participation, the marginalization of communities remains, along with a need to form different patterns of connectivity with those in power and claim to speak on their behalf. Could different approaches to doing research help to shift power towards the powerless? First, this article identifies four key aspects of the broader ethos of participatory, co-productive research. It then looks at text as a specific barrier to co-productive research, before describing a range of 'beyond text' approaches and tools that could contribute to more co-productive research. It looks at how ethos and tools were applied in case studies of the authors' research. We conclude that beyondtext methods need to be applied within a wider set of values which re-conceptualize the role of the researcher working with communities. This article concludes by discussing ways forward for reconciling the challenges that academics face in undertaking new methods while still needing to meet the needs of their text-bound profession.

\section{Community participation in research: an ethos or a set of tools?}

Researchers in the United Kingdom and other parts of Europe have been working in 'less than propitious circumstances' (Bond and Paterson, 2005, p. 331), and from a relatively low starting point in undertaking research with communities. Different contextual and disciplinary settings seek to challenge Western orthodoxies of research where these are about 'excluding the views of ordinary people' (Williamson and de Souza, 2010, p. 1). In Latin America, South Asia and North America, there has been a longer tradition of community-engaged research, and indeed, community involvement in the governance of research (Reardon, 1998; Lantz et al., 2001). Participatory 
research is closely allied with community development practice, for example 'community driven development' (Taylor, 2011), and 'critical community practice' (Butcher et al., 2007) which uses reflection in order to develop empowering and transformative practice. Different disciplines also offer strong traditions of participatory research, for example, critical and social geography (Pain, 2004), development studies (Gaventa, 2005), social policy (Bennett and Roberts, 2004), sociology and anthropology (ReitbergenMcCracken and Narayan, 1998; Falzone, 2004) and research into poverty (Narayan et al., 1999).

Participatory approaches, including participatory action research (PAR) and co-production, have been unevenly applied across and within disciplines, institutions and countries, but are part of an iterative process of overcoming power imbalances in research. They are characterized by a normative stance that challenges the position of communities and marginalized groups as 'subjects' in research, and instead sees them as having a right to be involved in research (Lister et al., 2000). These approaches propose that research is done in ways that promote and privilege the voice of the community, is respectful of local or indigenous practices and is culturally safe (Williamson and de Souza, 2010, p. 1). Documentation of participatory approaches to research illustrates specific sets of research tools and technical tips about process, for example in toolkits based on international research (ReitbergenMcCracken and Narayan, 1998). However, participatory approaches to research and moves towards co-production in research are also distinct in terms of broader ethos and approach.

Four key aspects to this broader ethos can be identified in the literature. First, transformational social goals. Robinson and Tansey suggest that some forms of participatory involvement of the subjects of research is 'dialogical' (2006, p. 152), i.e. involving a dialogue with participants at some point in the research process, but also have a transformative element to 'actively alter the social conditions in which they find themselves' (2006, p. 152). Second, acknowledging different claims to knowledge: 'Co-production of knowledge requires that [some] contributions.... are not privileged over what other[s] ... contribute... [and] that communication is not seen as a one-way transfer from a knowing subject to a supposedly ignorant one' (Pohl et al., 2010, p. 217), while at the same time, minimizing 'threats to ... the integrity of the research process' (Martin, 2010, p. 213). Third, recognition of dynamic interactions between researchers and the researched. Some have rejected the notion of a non-dynamic 'binary relationship' (Orr and Bennett, 2009; Pohl et al., 2010), and instead posited the idea of mutual learning and interaction between two parties with distinct roles and claims to knowledge. Co-production attempts to span boundaries and to blur the identities, but this involves deep challenges: 'Co-producing 
research entails tussling with the dialectic between unity and difference, sovereignty and interdependence, the self and the other. Co-producing research holds the potential for creative coalitions but also the possibility of the clash of civilizations' (Orr and Bennett 2010, p. 202). Fourth, following the ethos of research through into knowledge production processes. Standard methodologies tend to compound power dynamics, where the 'problem' is one that has been devised by researchers and funders of research. Partly, this is about a fundamental problem of the control of issue definition by the more powerful parties in research relationships (funders and academics). Partly, this is about timing and at what stage of the process research participants become involved.

An understanding of co-production in research therefore has the following elements: a more equal partnership with communities and practitioners; working in a dynamic relationship to understand issues, create knowledge and then implement findings for transformational social change. This approach to research is underpinned by respect for different bases for expertise and claims to knowledge, a research production process that allows genuine participation at all stages, and transparency in the values informing the inception of the work.

Challenges to power asymmetries would need to unpick a deeply rooted set of power relationships, tensions about different claims to knowledge and complex accountability and governance worlds. 'Interactive knowledge production' rests on developing a shared 'thought style' (Pohl et al., 2010, p. 271) within a 'boundary space' which facilitates different social worlds working together, with 'distinct lines of accountability to each' (Pohl et al., 2010, p. 268).

\section{The dominance of text in research}

All of this suggest that some of the barriers to co-productive research are greater than technical issues such as the application of specific participatory research methods. However, while ethos is central to co-producing research with communities, method is key in facilitating and enabling coproduction. The use of text, and therefore text-based research methods, can be seen as a cause and a symptom of the disempowerment of research subjects. It is a barrier to developing connectivities between academia and communities: 'privileging the voices of participants is about respect. Language is a matter of power and control, or colonisation and submission' (Williamson and de Souza, 2010, p. 5).

Text is the primary medium of academic research and contains within it power, privilege, exclusivity and exclusion (for outsiders to the academy) and inclusion for those within it. Conventions in academic text for specialist 
terms make them comprehensible only to those initiated into the discipline; codification in the form of the journal article or book is at the core of its exclusivity. Academics critique each other's work through text, but as a form of communication does not contain dialogical elements or easily allow for challenge within its form. For Walker (2010), academic practices can be a refuge from engagement, describing the peer review process as 'epistemological protectionism' which asserts monopoly rights to defining and legitimating knowledge.

Among others, historians, those in development studies, anthropologists and sociologists have attempted to rescue the value of people's verbal accounts of their lives and experiences. But even here, the writing up processes have been critiqued as damaging the integrity of the respondents' messages, and still involve a high degree of editorial control by the author (e.g. Parker, 2006, p. 293), and a lack of control of the subjects in the presentation of their experiences. End texts produced from research contain within them value judgements, interpretations and analysis that can sometimes be hidden, and presented as fact. Writing up of research includes academics interpreting the voices of interviewees from within the interviewee's own epistemological frameworks, as noted by Redwood (2008), who suggests that research is 'an inherently violent activity' on a symbolic or meta-physical level: 'What makes research violent is the way that moral choices, ethical and analytical decisions, representational practices and personal investments of the researcher are secreted away and so are made to appear natural and innocent' (p. 7).

So, where the primary medium of data collection, analysis, writing up and dissemination is academically orientated text, this has many implications for co-production in research. Exclusive and exclusionary text, privileging those within the profession, indicates a lack of respect for different claims to knowledge. A more equal partnership between communities and practitioners is made less likely when formalized, specialist text-based codes of the academy are used. Incomprehensible language located in sites and forms that are not accessible to 'outsiders' do little to enhance a transparent and dynamic relationship, or public-facing knowledge production. Where knowledge production is not public-facing, its ability to generate transformational social change is undermined.

Some have offered performative social science as a less violent alternative, arguing: 'By rethinking our relationships within communities and across disciplines such as the arts and humanities, we are presented with opportunities to move beyond imitation of "scientistic" reports in dissemination of our work and look towards means of (re)presentation that embrace the humanness of social science pursuits' (Jones, 2006, p. 67). Similarly, Glass (2008) suggests that researchers bring meaning 'alive', using art and 'raw images', developed through reflexive debates with participants. 


\section{'Beyond text'}

Focusing on how text is used can be one way to open up debate around much broader issues because of the exclusive and sometimes exclusionary dynamics it can represent (Williamson and de Souza, 2010). Beyond-text methods are more common in the dissemination of outputs than in other stages of the research process (e.g. see emphasis in Jones, 2006). While videos, posters, web blogs, presentation, performances and other methods of dissemination are positive moves, they do not tackle issues of participation throughout the process. 'Beyond text' can act as a point of difference, symbolizing a research ethos as well as a set of tools for research which facilitate co-production.

One beyond-text method that can be used in research design and data collection stages is storytelling, which is a familiar form to lay people and has been structured into specific verbal research methods which allow participants to evolve analytical thinking, broad themes and abstract concepts jointly with researchers. These ideas have been developed by writers across disciplines (Geertz, 1973; Feldman et al., 2004; Maynard-Moody and Musheno, 2006). Storytelling is an evolution of conventional qualitative research methods such as narrative interviewing, which can often remain researcher-led. Storytelling is designed to be a more open process which is researcher-facilitated and participant-led. Little and Froggett see storytelling as an inclusionary intervention (2010, p. 458) and suggest that it can help to represent complexity because ' ... it draws out different, often opposing strands and allows their co-existence within the framework of a narrative that can be shared' (2010, p. 470).

Speaking de-privileges text, but still privileges language. Visual methods can help people articulate their individual perspectives without (necessarily) words or text. In the social and natural sciences, there has long been extensive use of non-linguistic modes of representation - charts, models, diagrams - to express complex, inter-related ideas. Yet in conventional research, these visual methods are often as exclusionary of lay people as text, with highly technical formats and professional or disciplinary terms or concepts. Visual beyond-text methods open up research to a wider range of sources of non-linguistic representations, including the use of cartoons, hand-drawn images, images from popular media, photographs, installations, video, film and animation, art and painting, drama, dance and other forms of performance. Bexley and Fijn (2007) suggest visual approaches can be used at different stages in anthropological research including: as a research tool during fieldwork; as a method of analysing findings; and as a way of visualizing the field of study itself. Visual approaches are argued to be intuitive and more immediate or true to direct experience: 
'Seeing comes before words. The child looks and recognizes before it can speak. [...] It is seeing which establishes our place in the surrounding world; we explain that world with words, but words can never undo the fact that we are surrounded by it' (Berger, 1972, p. 7).

Purcell (2009) discusses the importance of 'critical photographic practice' in methods to meet community development objectives. There are a range of studies using these methods, such as in 'photovoice' (Killion and Wang, 2000) and photo-interviewing (Hurworth, 2003) which make use of the medium in the process of data collection. In the United States, Wang (2006) has developed a photovoice framework for research which allows structured discussion and interrogation to take place while avoiding preconceived, professional frameworks influencing the findings and instead opening up the line of enquiry to all participants (p. 151).

'Beyond text' can mean 'beyond words'; however, the rapid rise of 'new text' forms particular in mobile phone 'texting' and in social media could also be included in a loose definition of 'beyond (conventional) text' (Scearce, 2011). These forms offer new routes for re-negotiating text as something that could be controlled and owned by research participants. For example, although Twitter uses text, tweeters often use non-standard English, in-group abbreviations and phrases. Coupled with the 140-character limit, this format is a potentially more accessible, nonconventional text form. Some research has started to use social media applications such as Twitter and Facebook to empower participants (Boeck and Thomas, 2010).

As the format for this article might suggest, a commitment to 'beyond text' does not imply an absence of text, but rather a pluralism of tools alongside conventional text. So, beyond text, but not without text (Harrison, 2002; Bexley and Fijn, 2007).

\section{Potential and challenge in applying new methods: case studies from personal practice}

The article now turns to the authors' own practice in research, drawing on two contrasting examples. The first example demonstrates how an underlying ethos of co-production in research was constrained by the use of traditional research tools and the need for legitimacy which is associated with text outputs. The second example takes a project with a highly positivist ethos, but in which participants initiated beyond-text methods to re-balance unequal power relationships and re-assert control of the 'subjects' over research.

The first practice case study is of research with Gypsy and Traveller communities, which experience exclusion and are marginalized in myriad ways 
and 'othered' in the media (Richardson, 2006) and public and social spheres (Richardson and Ryder, 2012). Accommodation issues are critical for travelling communities which face wariness and sometimes hostility from settled communities and experience many instances of conflict over sites (Richardson, 2007). Research undertaken in 2010 by one of the authors of this article (J.R.) has sought to analyse the accommodation needs of Gypsies and Travellers in a county in England. The local council commissioned the work to meet government statutory requirements, which specifies what data should be collected, and how. The framework, issues and conceptualization of the issues were all pre-set.

In order to access the so-called hard-to-reach Gypsy and Traveller communities, community members were part of the research fieldwork team whose work included the design of the survey. They received training on undertaking survey work and undertook over 150 detailed surveys of Gypsy and Traveller accommodation needs. Community researchers then were consulted on the preliminary analysis of data and involved in focus groups to discuss key qualitative issues in further detail.

This research involved not only the use of community members as informants and co-researchers (Martin, 2010) but also attempted to form deeper co-productive and trust relationships, allowing for more open responses to questions. Members of Gypsy and Traveller communities were seen as core members of the project team; and perceived themselves to be integral to the success of the research. Travellers' perceptions of the process were the research process had been informative and helpful and had contributed to renewed confidence of participants. The Traveller interviewed at the end of the research said that: 'Overall it was worth doing. It has made me think more positively about being able to do something - rather than living each day and coping, but instead looking to future'.

Yet, community members also experienced tensions and a blurring of the lines between their roles as community interviewers (researchers) and being members of the community being interviewed (participants/subjects). Some of the tensions were between their independent research gathering role and the potential impacts of the accommodation assessment on the communities of which they were part: 'Unless councils are going to help, they should stop asking questions about it'. While community members saw potential for change in the future, they were concerned that there would be little immediate change for the community as a result of the research. Wider personal dilemmas included colluding with 'officialdom' and creating expectations which may not be fulfilled, and possible resentment: '[Travellers] get fed into a machine - it pisses people off'. One of the Travellers who was part of the research team described a feeling of the New Travellers being 'gawped at' and found the questionnaire format as 
overly intrusive, as if: 'someone following [you] around the house saying "so how do you wash up, how do you get dressed?"'. They expressed a sense that all aspects of their social worlds and life experiences were forced into pre-set categories and government-defined 'boxes' in a written questionnaire.

Participatory approaches to research have also been attempted by other researchers working with Gypsy and Traveller communities (Brown and Scullion, 2010) and there are arguments that using non-text tools in research is more culturally appropriate in communities with high levels of illiteracy. For example, Gypsies and Travellers have a wealth of experience in storytelling in the sharing of history and culture. Professional Gypsy storytellers (such as Richard O'Neill) undertake work in schools through the use of storytelling. Storytelling is a rich part of Gypsy and Traveller culture - it is not a research tool belonging to academics; the expertise lies with Traveller community members.

The second example is of research by another of the authors (L.R.; for a detailed account, see John et al., 2011). The project was a randomized controlled trial (RCT) of different types of lobbying by eight citizen interest groups of local councillors in the English local government. The citizen interest groups included a self-help group run by and for people with physical and learning disabilities and several small groups of young people aged between ten and twenty-one years old. They were recruited to deliver the lobbying interventions and as such were part of the research team delivering the research and trial, rather than the 'subjects'. The local councillors were the true subjects. The groups were recruited with full transparency about the nature of the trial, and volunteered to play their role. The subject of their lobbies, nature of the lobbying request and key local issues were all decided by the groups.

However, in practice, the project was constrained in having a fully co-productive relationship with the groups. Field experiments need to have a standardized intervention, in line with the hypotheses the academics wish to test, so the researchers chose a text-based intervention (i.e. the lobbying letter) partly because they were easier to standardize. Academics created a pro-forma for the design of the intervention into which each group's issues, requests and topics were edited by the academics.

The drafting of formal letters was perceived as difficult to make into a collective activity, and the groups felt this ran a risk of excluding members who had taken part in the discussions. Instead, the groups used media they were already familiar with and which better facilitated collective lobbying. The younger people preferred to use text messaging, Facebook or Twitter, and the disability advocacy group, face-to-face communication. Some of the groups had previously used film to document their activities and so put 
their lobbying into a short film. The films were placed on YouTube after the trial had completed. The use of beyond-text methods in the research for this case study was not initiated by the research team and was not originally part of the design of the project. The use of beyond-text approaches was generated as a reaction by research participants (with support from a community practitioner) to the overly dominant emphasis on text in the research by the academic partners. It enabled them to regain control over aspects of the process about which they felt uncomfortable.

\section{Discussion of case studies}

Only the first case study had an explicit commitment to a co-productive ethos, with the goal of changing living conditions for Gypsy and Travellers. In this work, there was a recognition of the contribution to knowledge that could be made by community members as part of the research team, and a dynamic relationship between team members. Despite the satisfaction of the community researchers with the research process, there were tensions between their community memberships and roles as 'independent' researchers, including concerns about collusion and whether change would be achieved. The second case study used the positivist method of RCTs, which inherently denies equal claims to the knowledge of the community groups. This ethos flowed through to the knowledge production processes which were academic-led and -driven. However, even here, there were transformational social goals as the project was designed to see whether citizen lobbying for change could be made more effective. There was also a dynamic relationship as the citizen interest groups were members of the research delivery team with full awareness of the research.

Neither of the practice case studies fully achieved or operationalized a co-productive ethos or even a deliberate use of beyond-text methods. However, they illustrate the importance of both in building a co-productive approach to research, particularly with marginalized communities. Demands associated with text were constraints to co-production in both projects. In both case studies, the groups working with researchers could be identified as marginalized, and groups for whom conventional text-heavy forms of communication were inappropriate. A more equal partnership with communities was hard to achieve because of the use of text, regardless of the underlying ethos of the research. In both case studies, treating the community participants as 'sub-contracted' parts of the research team - in the same way as any other research partner - did not enable a genuinely equal research partnership. Another element identified as necessary for co-production is that knowledge contributes to positive social change; this presented challenges in both projects. 


\section{Conclusion}

Despite these challenges, an explicit focus on text opened up wider debates about the nature of the research process and relationship between researchers and the researched. In this way, 'beyond text' could have symbolic value and open up new spaces with additional possibilities for stronger co-production. The symbolic value of 'beyond text' is to allow the expression of a more participatory ethos, providing tools for this ethos to be more meaningfully applied. Challenging the dominant form of expression of existing unequal power relationships sometimes stimulates a change of ethos. There is a dynamic relationship between method and ethos, as illustrated by the case studies. A co-productive ethos may amount to nothing more than good intentions if text-based methods do not offer space for them to fully participate. Participatory tools or processes in themselves can be disempowering if used without an underpinning ethos. Clements et al. (2008) warn against the fetishization of community participation processes (p. 3). In a dynamic two-way process, beyond-text methods in our case studies provided a symbolic way for communities to voice their dissatisfaction with gaps in a co-productive ethos and challenge academic-led processes.

Researchers should not be complacent about the application of more co-productive approaches in research, and inherent challenges, and significant changes they demand from researchers (Durose et al., 2011). Simply applying the label of 'co-production' to research does not mean scholars are truly delivering on their desired aims. Freire's Pedagogy of the Oppressed gives enough warning: 'The leaders cannot treat the oppressed as mere activists to be denied the opportunity of reflection and allowed merely the illusion of acting, whereas in fact they would continue to be manipulated - and in this case by the presumed foes of manipulation' (1970, p. 107). In the light of this cautionary injunction, the risk is that co-option of beyond-text methods by researchers, such as the Gypsy and Travellers' practice of storytelling, through the appropriation of the rich traditions and preferred practices of communities, may have the unintended consequence of being merely another means of disempowerment.

Tensions remain between traditional 'academic' outputs such as peerreviewed journal articles that are reliant on text and new and emerging methods driven by community members as part of PAR. Where research is co-produced, there may be difficulty in having clear lines of accountability in the process and the outcomes. Traditional academic texts have a finite number of named and identifiable 'authors'. Crediting the contributions of participants will require different types of outputs. Robinson and Tansey note 'overriding' importance of learning 'how to negotiate the boundaries and terms of engagement between the research and partner communities' 
(2006, p. 159). Saward describes 'representation as a practice' (2006, p. 316); co-production presents researchers with the challenge of 'how they represent' within their research.

Despite the long and rich traditions of participatory approaches in research originating in the Global South, the process of transfer of lessons from this work to the Global North, and particularly the United Kingdom, has not been a smooth one. One conclusion from our work is that toolkits focusing on specific research methods and other technical solutions are insufficient to challenge the underlying power dynamics which prevent their application. Co-produced research inherently re-conceptualizes the role of the researcher in working with communities, as more accepting of different claims to knowledge, operating within new shared spaces for acting, committed to social change, and perhaps, willing to trade-off the 'traditional' forms of academic reward for community benefit. Academic incentive structures in the United Kingdom privilege text-based outputs, in a context with a less strong tradition of community-engaged research. This suggests that any re-conceptualization will present a significant challenge to existing ways of doing research, and may require a powerful groundswell of change from researchers with enough confidence and commitment to generate new spaces and make these trade-offs. Colleagues from other international contexts where more progress has been made could offer support for these changes.

\section{Acknowledgements}

We are grateful for the input from academic and community colleagues at two workshops: the Roundtable, 'Academic-activists and activist-academics: making it work for communities \& knowledge', held at Trafford Hall, the home of the National Communities Resource Centre, Chester, UK, on 20 September 2011; the colloquium, 'Methodological Challenges in Participation Research' convened at the Instituto de Estudios Sociales Avanzados, Cordoba, Spain, on 4-5 November 2011.

\section{Funding}

This article draws on a scoping study supported by the Arts and Humanities Research Council (AHRC) as part of their Connected Communities Scoping Studies and Research Reviews programme.

Dr Yasminah Beebeejaun is a Lecturer in Planning at the Department of Planning, University of Manchester, UK. Her research interests are in urban sociology and planning and focuses on the construction of ethnic and gendered identities within cities, community engagement, and social justice. Her work is published in Urban Studies, Planning Theory and Practice, and 
Planning Practice and Research. She is an editorial board member of the Journal of Urban Affairs.

Dr Catherine Durose is a Senior Lecturer and Director of Research at the Institute for Local Government Studies at the University of Birmingham, UK. Catherine's research is situated in public administration and governance and concentrates on the changing relationships between the state, communities and citizens, with particular interest in local policy implementation and service delivery, practice and local knowledge, neighbourhood working and participation and empowerment. Catherine's recent work can be found in Public Administration, Political Studies, Policy and Politics and Local Government Studies.

James Rees is a Research Fellow at the Third Sector Research Centre at the University of Birmingham, UK. His research interests are in public services and the role of the third sector, urban and regional governance, and community and citizen engagement. He has published in Policy and Politics, International Journal of Urban and Regional Research and International Journal of Public Sector Management. He is an editorial board member of Voluntary Sector Review.

Joanna Richardson is a Principal Lecturer in the Department of Politics and Public Policy at De Montfort University, Leicester, UK. Her research focus is on conflict and co-production, particularly in planning for Gypsy and Traveller sites and has led a ESRC seminar series looking at this. Jo's recent publications include books for Policy Press on the impact of the recession and on equality for Gypsies and Travellers; and a book for the Chartered Institute of Housing on customers and insight. Other work has been published in Housing Studies and by the Joseph Rowntree Foundation.

Liz Richardson is a Senior Lecturer in Politics at the University of Manchester, UK. She conducts research on civic participation and citizenship, behaviour change techniques, neighbourhood governance, local politics and local government, public services, and public policy. She has an interest in methodological innovation including participatory research approaches, and experimental methods. Her work is published in the British Journal of Politics and International Relations, Social Science Quarterly, Parliamentary Affairs, and Policy and Politics.

\section{References}

Aldred, R. (2011) From community participation to organizational therapy? World Café and Appreciative Inquiry as research methods, Community Development Journal, 46 (1), 57-71.

Bennett, F. and Roberts, M. (2004) From Input to Influence: Participatory Approaches to Research and Inquiry into Poverty, JRF, York, UK.

Berger, J. (1972) Ways of Seeing, BBC/Penguin Books, London.

Bexley, A. and Fijn, N. (2007) Introduction: the power of vision and voice, The Asia Pacific Journal of Anthropology, 8 (4), 279-285.

Boeck, T. and Thomas, S. (2010) Amplified Leicester: Impact on Social Capital and Cohesion, NESTA, London. 
Bond, R. and Paterson, L. (2005) Coming down from the ivory tower? Academics' civic and economic engagement with the community, Oxford Review of Education, 31 (3), 331-351.

British Academy (2010) Past, Present and Future: The Public Value of the Humanities and Social Sciences, British Academy, London.

Brown, P. and Scullion, L. (2010) Doing research with Gypsy-Travellers in England: reflections on experience and practice, Community Development Journal, 45 (2), 169-185.

Butcher, H., Banks, S., Henderson, P. et al. (2007) Critical Community Practice, The Policy Press, Bristol, UK.

Catalani, C. and Minkler, M. (2009) Photovoice: a review of the literature in health and public health, Health Education \& Behavior, 37 (3), 424-451.

Clements, D., Donald, A., Earnshaw, M. et al. (eds) (2008) The Future of Community (Reports of a Death Greatly Exaggerated), Pluto Press, London.

Denis, J.L. and Lomas, J. (2003) Convergent evolution: the academic and policy roots of collaborative research, Journal of Health Services Research and Policy, 8 (S2), 1-6.

Durose, C., Greasley, S. and Richardson, L. (2009) Changing Local Governance, Changing Citizens, The Policy Press, Bristol, UK.

Durose, C., Beebeejaun, Y., Rees, J. et al. (2011) Towards Co-production in Research with Communities, AHRC Connected Communities Programme Scoping Studies, AHRC, London.

Falzone, P. (2004) Transcendent ethnography, Action Research, 2 (3), 326-344.

Feldman, M.S., Skoldberg, K., Brown, R.N. et al. (2004) Making sense of stories: a rhetorical approach to narrative analysis, Journal of Public Administration Research and Theory, 14 (2), 47-170.

Foucault, M. (1980) Power/Knowledge: Selected Interviews and Other Writings 1972-1977, in ed. C. Gordon. Pantheon, New York, NY.

Freire, P. (1970) Pedagogy of the Oppressed, Continuum, London.

Gallaher, A. (1971) Plainville: the twice-studied town, in A. Vidich, J. Bensman and M. Stein, eds, Reflections on Community Studies, Harper and Row, New York, NY, pp. 285-303.

Gaventa, J. (2005) Claiming Citizenship: Rights, Participation and Accountability, Zed Books, London.

Geertz, C. (1973) The Interpretation of Cultures, Basic Books, New York, NY.

Ghose, R. (2007) Politics of scale and networks of association in public participation GIS, Environment and Planning A, 39 (8), 1961-1980.

Glass, N. (2008) Interrogating the conventional boundaries of research methods in social sciences: the role of visual representation in ethnography, Forum: Qualitative Social Research, 9 (2), Art. 50.

Harrison, B. (2002) Seeing health and illness worlds - using visual methodologies in a sociology of health and illness: a methodological review, Sociology of Health $\mathcal{E}$ Illness, 24 (6), 856-872.

Hurworth, R. (2003) Photo-interviewing for research, Social Research Update, 40, 1-3.

John, P., Cotterill, S., Moseley, A. et al. (2011) Nudge, Nudge, Think, Think: Experimenting with Ways to Change Civic Behaviour, Bloomsbury Academic, London. 
Jones, K. (2006) A biographic researcher in pursuit of an aesthetic: the use of arts-based (re)presentations in 'performative' dissemination of life stories, Qualitative Sociology Review, II (1), 66-85.

Killion, C. and Wang, C. (2000) Linking African American mothers across life stage and station through photovoice, Journal of Health Care for the Poor and Underserved, 11 (3), 310-325.

Lantz, P. M., Viruell-Fuentes, E., Israel, B. A. et al. (2001) Can communities and academia work together on public health research: evaluation results from a community-based participatory research partnership in Detroit, Journal of Urban Health, 78, 495-507.

Lister, R., Beresford, P., Green, D. et al. (2000) Where are 'the poor' in the future of poverty research?, in J. Bradshaw and R. Sainsbury, eds, Researching Poverty, Ashgate, Aldershot, UK.

Little, R. and Froggett, L. (2010) Making meaning in muddy waters: representing complexity through community based storytelling, Community Development Journal, 45 (4), 458-473.

Martin, S. (2010) Co-production of social research: strategies for engaged scholarship, Public Money and Management, 30 (4), 211-218.

Maynard-Moody, S. and Musheno, M. (2006) Stories for research, in D. Yanow and P. Schwartz-Shea, eds, Interpretation and Method: Empirical Research Methods and the Interpretive Turn, ME Sharpe, New York, NY.

Narayan, D., Patel, R., Schafft, K. et al. (1999) Can Anyone Hear Us? Voices from 47 Countries, Vol. 1, The World Bank, Washington, DC.

Orr, K. M. and Bennett, M. (2009) Reflexivity in the co-production of academic-practitioner research, Qualitative Research in Organisations and Management, 4, 85-102.

Orr, K. M. and Bennett, M. (2010) Editorial, Public Money and Management, 30 (4), 199-203.

Pain, R. (2004) Social geography: participatory research, Progress in Human Geography, 28 (5), 652-663.

Parker, T. (2006) Lighthouse, Eland Publishing, London.

Pearce, J. (2008) 'We Make Progress Because We Are Lost': Critical Reflections on Co-producing Knowledge as a Methodology for Researching Non-Governmental Public Action, LSE, London.

Pohl, C., Stephan Rist, S., Zimmermann, A. et al. (2010) Researchers' roles in knowledge co-production: experience from sustainability research in Kenya, Switzerland, Bolivia and Nepal, Science and Public Policy, 37 (4), 267-281.

Porter, L. (2010) Unlearning the Colonial Cultures of Planning, Ashgate, Aldershot, UK.

Purcell, R. (2009) Images for change: community development, community arts and photography, Community Development Journal, 44 (1), 11-122.

Reardon, K. (1998) Enhancing the capacity of community-based organizations in East St. Louis, Journal of Planning Education and Research, 17, 323-333.

Redwood, S. (2008) Research less violent? Or the ethics of performative social science, Forum: Qualitative Social Research, 9 (2), Art. 60. 
Reitbergen-McCracken, J. and Narayan, D. (1998) Participation and Social Assessment, World Bank Publications, Washington, DC.

Richardson, J. (2006) Talking about Gypsies: the use of discourse as control, Housing Studies, 21 (1), 77-97.

Richardson, J. (2007) Contentious Spaces: The Gypsy/Traveller Site Issue, CIH/JRF, Coventry.

Richardson, L. and Le Grand, J. (2002) Outsider and insider expertise: the response of residents of deprived neighbourhood to an academic definition of social exclusion, Social Policy and Administration, 36, 496-515.

Richardson, J. and Ryder, A. (eds) (2012) Gypsies and Travellers: Empowerment and Inclusion in British Society, The Policy Press, Bristol, UK.

Riger, S. (1992) Epistemological debates, feminist voices: science, social values and the study of women, American Psychologist, 47 (6), 730-740.

Robinson, J. and Tansey, J. (2006) Co-production, emergent properties and strong interactive social research: the Georgia Basin Futures Project, Science and Public Policy, 33 (2), 151-160.

Saward, M. (2006) The representative claim, Contemporary Political Theory, 5 (3), 297-318.

Scearce, D. (2011) Connected Citizens: The Power, Peril and Potential of Networks, Knight Foundation, Miami, FL.

Taylor, M. (2011) Public Policy in the Community, 2nd edn, Palgrave Macmillan, Basingstoke, UK.

Umemoto, K. (2001) Walking in another's shoes: epistemological challenges in participatory planning, Journal of Planning Education and Research, 21, 17-31.

Walker, D. (2010) Debate: do academics know better or merely different?, Public Money and Management, 3 (4), 204-206.

Wang, C. (2006) Youth participation in photovoice as a strategy for community change, Journal of Community Practice, 14, 147-161.

Williamson, A. and de Souza, R. (2010) Researching with Communities: Grounded Perspective on Engaging Communities in Research, Muddy Creek Press, London, UK/ Auckland, New Zealand.

Wingenbach, E. and Phillips, C. (2004) 'When is a politics of presence necessary to democratic legitimacy?', paper presented to the Western Political Science Association Meeting, 3 March 2004, Portland, OR. 